\title{
Within- and between-nervous-system inhibition of return: Observation is as good as performance
}

\author{
TIMOTHY N. WeLSH \\ University of Calgary, Calgary, Alberta, Canada \\ JAMES LyONS \\ McMaster University, Hamilton, Ontario, Canada \\ DANIEL J. WeEkS \\ Simon Fraser University, Burnaby, British Columbia, Canada \\ J. Greg ANSON \\ University of Otago, Dunedin, New Zealand \\ Romeo ChuA \\ University of British Columbia, Vancouver, British Columbia, Canada \\ AND \\ Jocelyn Mendoza and Digby Elliott \\ McMaster University, Hamilton, Ontario, Canada
}

\begin{abstract}
Inhibition of return (IOR) has been shown to occur when an individual returns to a target location (withinperson IOR) and when an individual moves to a location just engaged by another individual (between-person IOR). Although within- and between-person IOR likely result from the same inhibitory mechanisms, different processes must activate these mechanisms following the performance and observation of action. Consistent with the suggestion that the mirror neuron system may be responsible for activating the inhibitory mechanisms behind IOR on observation trials, between-person IOR was only detected under restricted viewing conditions known to activate mirror neurons. These results indicate that mirror neuron system may be involved in both higher-order and automatic cognitive behavior.
\end{abstract}

Humans have evolved as social animals. Initially, humans interacted with one another to satisfy basic needs of survival. Then, as now, the success of a group and the development of skills depended on the ability to observe and understand the actions of more skillful peers (see, e.g., Bandura, 1977; Blandin, Lhuisset, \& Proteau, 1999). In support of this notion that the observation and understanding of another's actions is important for shaping behavior, a network of neurons, the mirror neuron system, seems to have developed to serve these specific purposes (Rizzolatti \& Craighero, 2004).

The mirror neuron system is a collection of neurons in the prefrontal and posterior parietal cortices that increase in firing rate during both the performance of action and the observation of another individual's action (di Pellegrino, Fadiga, Gallese, \& Rizzolatti, 1992). Since current evidence suggests that the actions of others influences higher-order cognitive processes such as language and motor learning (Rizzolatti \& Craighero, 2004), Welsh et al. (2005) recently sought to determine whether action observation can also influence mechanisms of selective attention. Specifically, they investigated whether the response of one individual would affect the speed at which an observer could select and program a subsequent response through a comparison of within- and betweenperson inhibition of return.

Inhibition of return (IOR) refers to the slowing of responses to targets that are presented at the same location as a previous attention-capturing event (Posner \& Cohen, 1984) or a response (Maylor \& Hockey, 1985). It has been suggested that the mechanisms underlying IOR developed to facilitate search patterns by biasing attention and/or action away from previously attended locations (Klein, 1988; Klein \& MacInnes, 1999). If this account is correct, IOR should be observed when an individual responds to a target at a location where that individual or another individual had recently searched. That is, if two individuals are engaged in a coordinated search for a tar-

T. N.Welsh, twelsh@kin.ucalgary.ca 
get, both within- and between-person IOR effects should be observed, because it would be inefficient for either individual to reinvestigate a location, regardless of who initially searched it.

Welsh et al. (2005) tested the social search hypothesis by asking pairs of participants to sit opposite each other and perform a series of responses to targets that randomly appeared at one of two locations. The responses were completed in an alternating-paired order such that one participant completed two responses followed by two responses from their partner (AABBAA ...). This design permitted the examination of within- (AA and $\mathrm{BB}$ trials) and between-IOR (AB and BA trials). In support of the social search hypothesis, response initiation times were longer to repeated targets than to different targets on both within- and between-person trials. Importantly, IOR was observed on both within- and between-person trials, and the magnitudes of these IOR effects were not different, suggesting that similar mechanisms were responsible for both effects. Although the same mechanisms likely caused within- and between-person IOR, the neural events that activated these inhibitory mechanisms must have been different. Consistent with previous motor-based explanations of IOR, within-person IOR was thought to result from inhibitory mechanisms that were elicited following the programming and completion of the first response to impede the reactivation of that specific response (Rafal, Calabresi, Brennan, \& Sciolto, 1989). In contrast, because the participants did not program responses on observation trials, Welsh et al. hypothesized that the mirror neuron system became active during response observation and that this activity mimicked the neural codes associated with the performance of the actual movement on the withinperson trials, subsequently evoking the mechanisms that cause IOR.

Although the observation of the response seemed to be the critical factor behind between-person IOR in the Welsh et al. (2005) studies, it is not the only possibility. An alternative explanation is that the motion associated with the response evoked the mechanisms of IOR rather than the response per se. Because the onset of motion is known to capture attention (Abrams \& Christ, 2003), it might have been that the onset of the motion of the partner's hand caused attention to be shifted to the target location, subsequently activating IOR at the location of the reversal point of the movement. The present experiments contrasted the mirror system and motion explanations of between-person IOR by investigating if between-person IOR would be observed under conditions of restricted action observation known to activate mirror neurons in nonhuman primates. For example, there are mirror neurons that respond to the presentation of the action effect (Kohler et al., 2002). In addition, mirror neurons are activated even when the observer does not see the effect of the action but does know what action is being performed (Fogassi et al., 2005; Umiltà et al., 2001). The present experiments were conducted to determine whether IOR would occur when observers only saw and heard the effect of their partner's response (partial-vision condition in Experiment 1), only saw an early section of their part- ner's action (partial-vision condition in Experiment 2A), or saw a nonbiological motion toward a target location (Experiment 2B). If the mirror neuron system explanation is correct, and knowledge of the response is the determining factor behind between-person IOR, then betweenperson IOR should be detected in Experiments 1 and 2A, but not in Experiment 2B. If the motion associated with the movement of the hand to and from a location causes between-person IOR, then between-person IOR will only be detected when observers witnessed the entire response (full-vision conditions in both Experiments 1 and 2A). Finally, if motion toward a target location alone causes a shift of attention that activates the mechanisms of IOR, then IOR will be observed in all conditions (including, critically, Experiment 2B).

\section{EXPERIMENT 1}

Experiment 1 was designed to determine if observation of the response effect alone would evoke between-person IOR. As such, participants in the partial-vision condition were allowed to see and hear the termination of their partner's response, but were prevented from seeing the onset of their partner's target and the trajectory of their partner's response (Kohler et al., 2002).

\section{Method}

Participants. Six pairs of women and four pairs of men from the McMaster University community participated in Experiment 1. Participants were right-handed, between the ages of 19 and 24 years, naive to the purpose of the study, and financially compensated. Each participant gave written informed consent prior to participating in any experiment. The procedures of all experiments were approved by the McMaster University Research Ethics Board.

Apparatus. The apparatus consisted of a metal box containing four buttons (see Figure 1). The two peripheral buttons contained red LEDs that illuminated to indicate the target location for a given trial. A cross positioned in the center of the box served as a fixation marker. A custom program randomly displayed target stimuli and recorded the time elapsed from target onset until home position release (reaction time, or RT) and the time from home position release until target button contact (movement time, or MT).

Task and experimental design. Each pair of observers completed 24 blocks of 33 successive aiming movements to target stimuli in one of the two locations. During each series of movements, participants (A and B) began with the index finger of the dominant hand on the start position and moved that finger as fast and accurately as possible to the illuminated button. The location of the target for each trial was random, with the constraints that left and right locations contained the target an equal number of times and that no target appeared at one location more than four times in succession. Participants completed the sequence of movements in an AABBAABB ... pattern, so that A made two successive aiming movements, then $\mathrm{B}$ made two successive movements, and so on. The target location was indicated by an $80-\mathrm{msec}$ illumination of one of the peripheral buttons. Once the responding participant had depressed a button, 1,000 msec elapsed, allowing that participant to return "home" and prepare for the next trial. Because total response times ranged from $326-755 \mathrm{msec}$, the interstimulus interval (ISI) was $1,326-1,755 \mathrm{msec}$.

Vision of the environment was controlled by liquid crystal goggles (Translucent Technologies, Toronto). Throughout the experiment, both participants wore sets of goggles that were typically transparent. The lenses only became opaque on observation trials in the partial-vision condition. Thus, the lenses were transparent to 
allow an unrestricted view each time participants were required to move or to observe their partner's responses on full-vision trials. However, during observation trials in the partial-vision condition, the lenses of the observers' goggles became opaque $20 \mathrm{msec}$ prior to the onset of each of their partner's targets and remained opaque until their partner contacted a target button (see Figure 2). Thus, the observer would see the partner's finger on the target location and the return of the finger to the home position, but not the target stimulus or the movement to the target. Each participant completed 12 blocks of trials in the partial- and full-vision conditions. Participants completed the first 12 blocks in one condition and then switched to the other condition.

\section{Results and Discussion}

RT and MT data for trials on which participants broke the alternation pattern or went to the incorrect location were eliminated from the data set. Because the response pattern was broken on these incorrect trials, the data for the trial following the error were also removed. From $0 \%$ to $4 \%$ of trials per pair were removed for these reasons. In addition, trials on which RTs were less than $100 \mathrm{msec}$ (anticipation error) or greater than $1,000 \mathrm{msec}$ (inattention error) were removed $(0.5 \%-3 \%$ of trials). Once these data were eliminated, mean values of RT and MT were calculated and submitted to separate person (same, different) $\times$ target (same, different) $\times$ vision condition (full, partial) within-subjects ANOVAs. All significant effects are reported. Post hoc analysis of significant interactions in all studies was performed using Tukey's HSD $(p<.05)$.

The only significant effect in MT was a main effect for person $[F(1,19)=14.62, p<.005]$, which revealed that participants completed their movement in less time on the second of their two movements (same-person $\mathrm{MT}=218 \mathrm{msec}$ and different-person MT $=223 \mathrm{msec}$ ). This repeated-person advantage was also observed in RT $[F(1,19)=34.01, p<.001$; same-person $\mathrm{RT}=270 \mathrm{msec}$ and different-person RT $=283 \mathrm{msec}$. A significant interaction between person and vision condition, however, revealed that the repeated-person advantage was greater in the full-vision condition than in the partial-vision condition $[F(1,19)=20.77, p<.001]$.

Of greater theoretical interest, the analysis of RTs revealed that participants were slower at initiating movements to the location of the previous response (same-target $\mathrm{RT}=285 \mathrm{msec}$ ) than to the other location (different-target $\mathrm{RT}=268 \mathrm{msec})[F(1,19)=97.32, p<.001 ;$ see Table 1] . Importantly, no interactions involving person and target were significant in RT (all $F$ ratios $<1$ ). Subsequent paired $t$ tests comparing same and different target RTs on different-person trials revealed IOR effects in both fullvision $[t(19)=5.35, p<.001]$ and partial-vision $[t(19)=$ $6.67, p<.001]$ conditions. The lack of significant interactions involving person and target and the subsequent $t$ test analysis indicated that (1) IOR was present following the observation of another person's response; (2) within- and between-person IOR effects were equivalent; and (3) the magnitudes of between-person IOR effects were similar when the observer saw either the full response or only the endpoint (Figure 3A).

\section{EXPERIMENT 2}

Although the results of Experiment 1 support the mirror neuron system hypothesis, they do not completely discount an attention explanation. The results do not rule out this alternative because participants still heard the contact of their partner's finger on a lateralized target button and saw the movement of the effector as it returned from to the home position. Thus, attention-capturing events still occurred at the engaged target location in the partial-vision condition in Experiment 1. Experiments $2 \mathrm{~A}$ and $2 \mathrm{~B}$ were conducted to parse out the possible contributions of knowledge of the response and of attention-capturing events to between-person IOR.

Experiment 2A separated the distinct contributions to between-person IOR of knowledge of the response effect

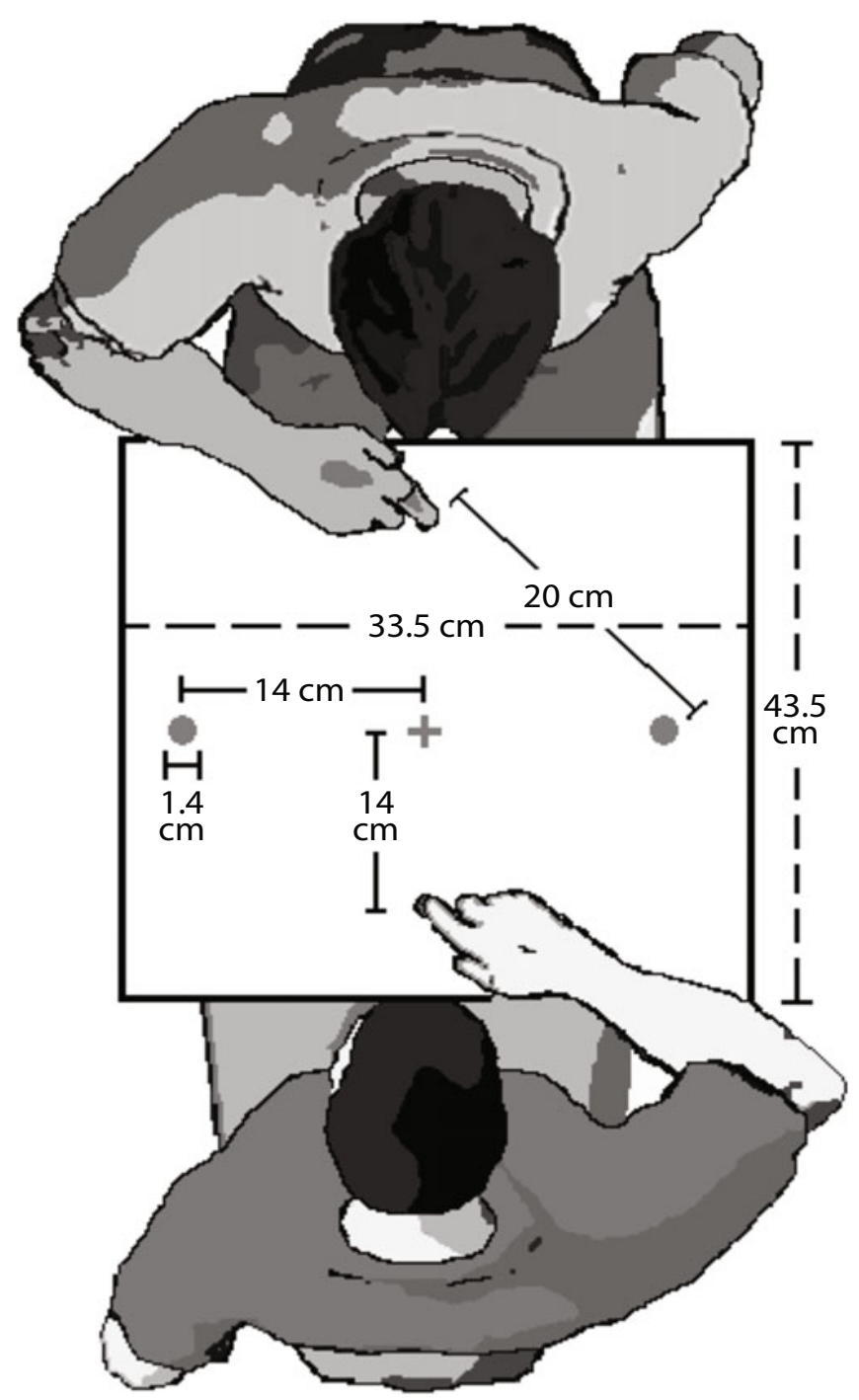

Figure 1. A diagram of the movement apparatus and participants. Measurements are not to scale. 

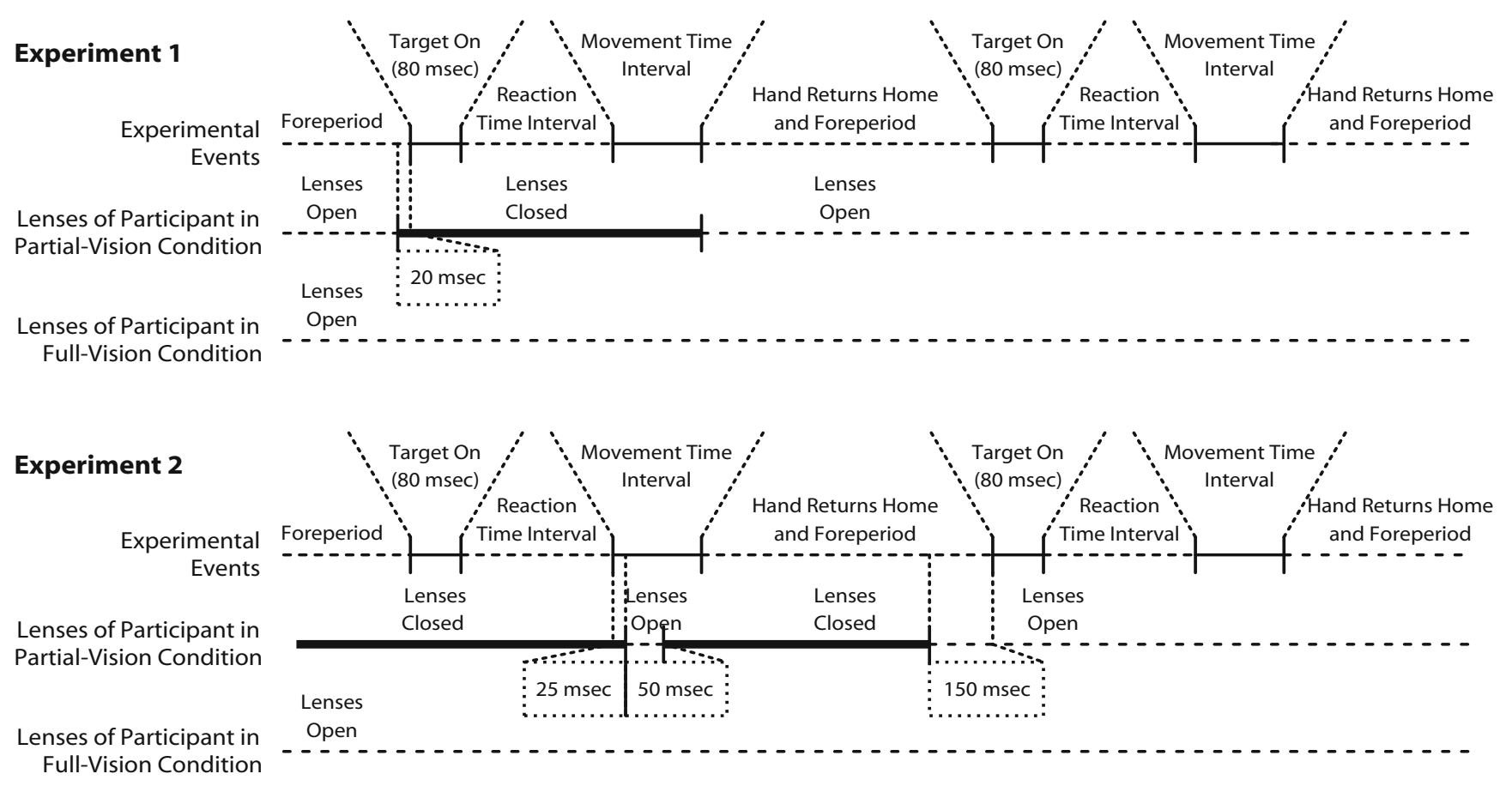

Figure 2. Time line of experimental events for Experiments 1 and 2.

and of attention-capturing events at the target location. Attention-capturing events at the target location were eliminated by preventing observers from hearing button contact and from seeing any more than an early section of the response. Thus, Experiment $2 \mathrm{~A}$ determined whether the between-person IOR effect would be elicited when the observer did not receive direct information about the endpoint of the response, but did receive enough information to know, or at least predict, the effect (see Umiltà et al., 2001; Wilson \& Knoblich, 2005).

Experiment 2B determined whether the observation of a response or of a stimulus moving toward a target location activated the processes of IOR on observation trials. Participants in Experiment 2B completed movements under the same conditions as in Experiment 2A, except that their partner's response was replaced by a rectangle projected onto the workspace. If between-person IOR is the result of motion alone, then movement of the rectangle toward one of the targets will evoke IOR. However, if knowledge of the response is the determining factor behind betweenperson IOR, then IOR will not be observed following the movement of the rectangle.

\section{Experiment 2A}

\section{Method}

Participants. Ten new pairs of individuals from the same population participated in Experiment 2A.

Apparatus, task, and experimental design. The apparatus, task, and experimental design of Experiment $2 \mathrm{~A}$ were the same as those used in Experiment 1, with the following exceptions. First, the goggles of the observer in the partial-vision condition (Participant A) changed from the transparent to the opaque state $20 \mathrm{msec}$ prior to target onset and remained opaque until $25 \mathrm{msec}$ after the partner (Participant B) had initiated the first response. Participant A's lenses remained transparent for $50 \mathrm{msec}$ and became opaque again, with the lenses remaining opaque until $25 \mathrm{msec}$ after Participant B had initiated the second response. After the second 50-msec window of vision, the lenses became opaque once again, until $150 \mathrm{msec}$ prior to the onset of Participant A's first target. The lenses then remained in a transparent state until $20 \mathrm{msec}$ before the onset of their partner's next target (see Figure 2). Because mean movement times in Experi-

Table 1

Means $(M)$ and Standard Deviations (SD) for Reaction Times and Movement Times (in Milliseconds) for Experiments 1 and $2 \mathrm{~A}$, As a Function of Vision Condition, Person Responding, and Target

\begin{tabular}{|c|c|c|c|c|c|c|c|c|}
\hline \multirow{3}{*}{$\begin{array}{c}\text { Dependent } \\
\text { Variable and } \\
\text { Vision Condition }\end{array}$} & \multicolumn{4}{|c|}{ Same Person } & \multicolumn{4}{|c|}{ Different Person } \\
\hline & \multicolumn{2}{|c|}{$\begin{array}{c}\text { Same } \\
\text { Location }\end{array}$} & \multicolumn{2}{|c|}{$\begin{array}{l}\text { Different } \\
\text { Location }\end{array}$} & \multicolumn{2}{|c|}{$\begin{array}{c}\text { Same } \\
\text { Location }\end{array}$} & \multicolumn{2}{|c|}{$\begin{array}{l}\text { Different } \\
\text { Location }\end{array}$} \\
\hline & $M$ & $S D$ & $M$ & $S D$ & $M$ & $S D$ & $M$ & $S D$ \\
\hline \multicolumn{9}{|c|}{ Experiment 1} \\
\hline Reaction Time & & & & & & & & \\
\hline Full vision & 276 & 30 & 257 & 34 & 294 & 42 & 276 & 34 \\
\hline Partial vision & 281 & 33 & 264 & 31 & 288 & 35 & 274 & 33 \\
\hline \multicolumn{9}{|l|}{ Movement Time } \\
\hline Full vision & 220 & 66 & 219 & 62 & 223 & 66 & 226 & 69 \\
\hline Partial vision & 216 & 63 & 216 & 63 & 222 & 66 & 222 & 69 \\
\hline \multicolumn{9}{|c|}{ Experiment $2 \mathrm{~A}$} \\
\hline Reaction Time & & & & & & & & \\
\hline Full vision & 267 & 23 & 248 & 23 & 283 & 28 & 268 & 24 \\
\hline Partial vision & 269 & 18 & 257 & 24 & 283 & 42 & 275 & 47 \\
\hline \multicolumn{9}{|l|}{ Movement Time } \\
\hline Full vision & 194 & 47 & 192 & 44 & 195 & 46 & 198 & 47 \\
\hline Partial vision & 185 & 39 & 187 & 39 & 192 & 43 & 193 & 44 \\
\hline
\end{tabular}


ment $2 \mathrm{~A}$ ranged from 121 to $337 \mathrm{msec}$, the $50-\mathrm{msec}$ window allowed observers in the partial-vision condition to see approximately the initial $1 / 4-1 / 3$ of their partner's movement. In addition to having a restricted view of the environment, observers in the partial-vision condition were prevented from hearing any response-related effects by a white noise mask that was constantly presented via a set of headphones. Thus, observers in the partial-vision condition in Experiment $2 \mathrm{~A}$ did not see or hear the initiation or termination of their partner's responses or of the target stimuli that evoked the responses, but saw enough of the response to determine the movement endpoint (i.e., the goal of the response; Fogassi et al., 2005; Umiltà et al., 2001). Finally, because mean total response time in Experiment $2 \mathrm{~A}$ ranged from 323 to $657 \mathrm{msec}$, the ISI was $1,323-1,657 \mathrm{msec}$.

\section{Results and Discussion}

The data from two pairs of participants were removed because of technical problems. The RT and MT data from the remaining 16 participants were submitted to the same screening procedures and statistical tests that were employed in Experiment 1 . From $0.5 \%$ to $6 \%$ of trials per pair were eliminated.

The only significant effect in MT was a main effect for person $[F(1,15)=7.28, p<.05]$ that revealed a replication of the repeated-person advantage (same-person $\mathrm{MT}=190 \mathrm{msec}$ and different-person MT $=195 \mathrm{msec}$ ). This repeated-person advantage was also replicated in RT $[F(1,15)=17.57, p<.001$; same-person $\mathrm{RT}=260 \mathrm{msec}$ and different-person RT $=277 \mathrm{msec}]$. The magnitude of the repeated-person advantage was not dependent on vision condition, as the advantage in Experiment 1 had been $[F(1,15)<1]$.

The analysis of RTs revealed an overall IOR effect $[F(1,15)=64.88, p<.001$; same-target $\mathrm{RT}=276 \mathrm{msec}$, different-target RT $=262 \mathrm{msec}]$. However, the magnitude IOR was mediated by vision condition. Post hoc analysis of the interaction between vision condition and target $[F(1,15)=5.54, p<.05]$ revealed that IOR in the fullvision condition $(17 \mathrm{msec})$ was greater than IOR in the partial-vision condition $(10 \mathrm{msec})$. To ensure that IOR was statistically reliable in both within- and between-person trials in the partial-vision condition, same-target RTs were compared with different-target RTs on both within- and between-person trials in the partial-vision condition using separate one-tailed $t$ tests. This $t$-test analysis revealed that same-target RTs were longer than different-target RTs in both within-person $[t(15)=2.95, p<.01]$ and betweenperson $[t(15)=2.90, p<.01]$ trials. Thus, although IOR was smaller overall in the partial-vision condition, perhaps because the white noise masked important auditory information on all trials, within- and between-person effects of IOR were equivalent within each vision condition (Figure 3B). Finally, there were no other significant interactions involving person $(p>.20)$.

\section{Experiment 2B}

\section{Method}

Participants. Sixteen new individuals from the same population participated in Experiment 2B.

Apparatus, task, and experimental design. The apparatus, task, and experimental design employed in Experiment $2 \mathrm{~B}$ were the same as those of Experiment 2A, except that participants were tested individually and the responses of the second participant were

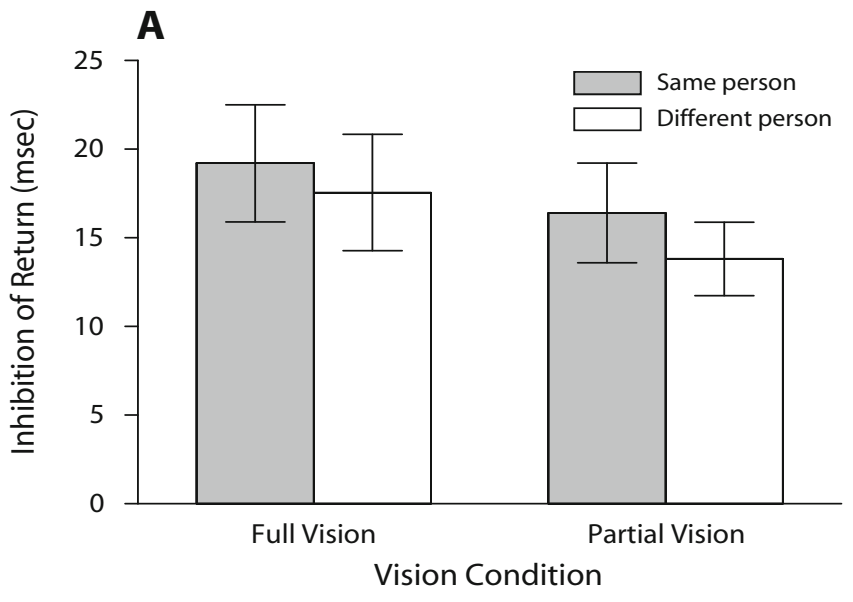

B

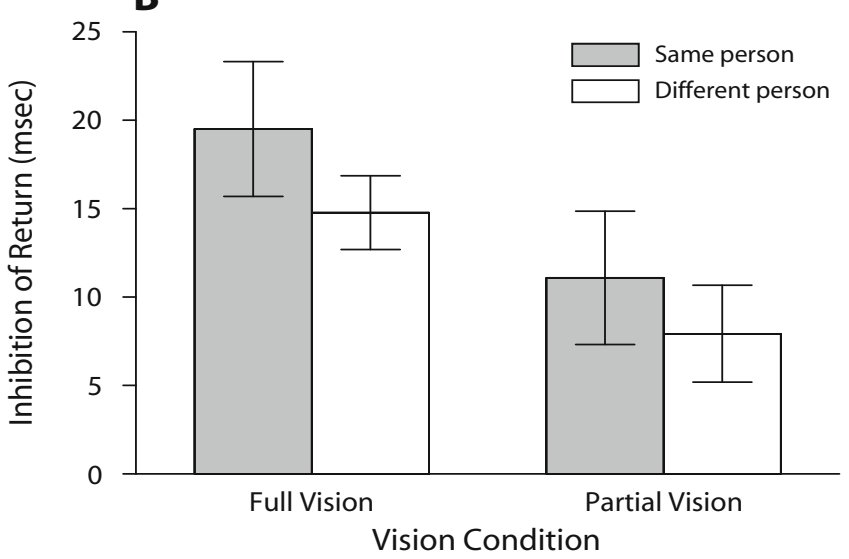

Figure 3. Mean inhibition of return as a function of vision condition and person responding for Experiment 1 (A) and Experiment $2 A$ (B). Inhibition of return (IOR) was calculated by subtracting different-target reaction time (RT) from same-target RT. Solid bars represent mean within-person IOR. Open bars represent mean between-person IOR. Standard error of the mean bars are shown.

represented by the projected image of a white rectangle $(2.5 \mathrm{~cm}$ long $\times 1 \mathrm{~cm}$ wide). Because the rectangle was designed to mimic the index finger of the partner in Experiment 2A, the rectangle was projected over the home position throughout a block, except during the two 50-msec windows of vision afforded to the participant on the observation trials. During these $50-\mathrm{msec}$ windows, the rectangle was repositioned to a location that was $1 / 4$ of the distance to one of the target locations. Thus, in the same way that observers saw the first $1 / 4$ of their partner's movements in the partial-vision condition of Experiment 2A, the changing of the location of the rectangle made it appear as though it moved $1 / 4$ of the way toward a target location. ${ }^{1}$ Based on the data from Experiment 2A, there was 1,293 $\mathrm{msec}$ from the moment observers lost vision of the second virtual movement until the onset of their first target.

\section{Results and Discussion}

After the RT and MT data for error trials were removed ( $1 \%-5 \%$ per participant), mean values of RT and MT were calculated and submitted to separate preceding movement (participant's, virtual) $\times$ target (same, different) withinsubjects ANOVAs. 


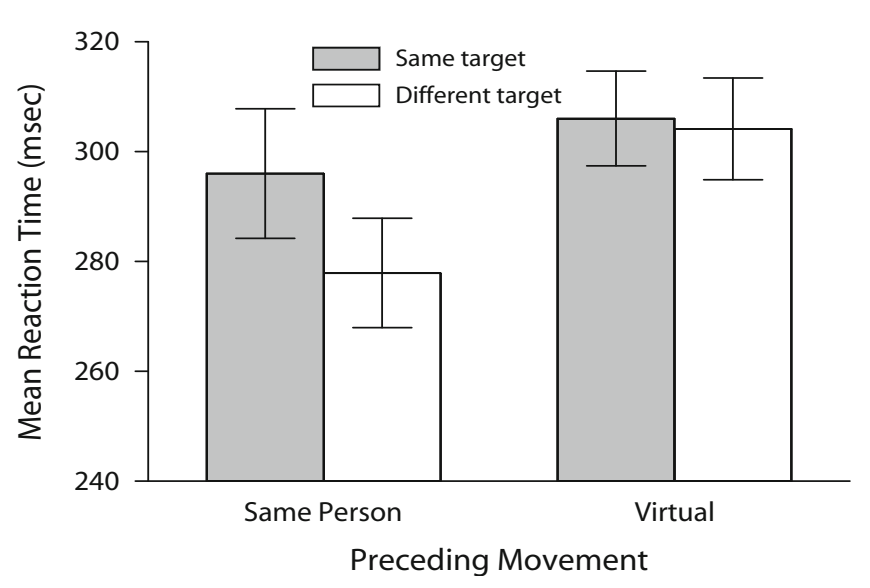

Figure 4. Mean reaction times as a function of preceding movement and target for Experiment 2B. Standard error of the mean bars are shown.

The analysis of MTs did not reveal any significant effects. The analysis of RTs revealed main effects for preceding movement $[F(1,15)=16.08, p<.005]$ and target $[F(1,15)=22.00, p<.001]$ and a significant interaction between these factors $[F(1,15)=12.11, p<.005]$. As can be seen in Figure 4, IOR was only observed when participants followed their own responses. That is, RTs for movements toward the same location as the participant's own previous response were slower than those to the nonresponded-to location, whereas RTs for responses following the movement of the rectangle were unaffected by the direction of the rectangle's movement. Thus, a comparison of the results of Experiments $2 \mathrm{~A}$ and $2 \mathrm{~B}$ indicates that it is knowledge of the response, not just motion, that activates the processes of IOR on observation trials. ${ }^{2}$ In addition, because the LCD goggles prevented the participants in Experiments 2A and 2B from seeing an actual target location after the $50-\mathrm{msec}$ window of vision, it is unlikely that any shift of attention or eye movement to a target, or even to a general area of space, was responsible for the between-person IOR in Experiment 2A.

\section{GENERAL DISCUSSION}

It is well established that reaction times to targets that are presented at the same location as a previous attention-capturing stimulus are longer than those to targets presented at any other location (i.e., IOR). Welsh et al. (2005) recently demonstrated that the inhibitory mechanisms behind IOR are also activated by the observation of another individual's action. The purpose of the present experiments was to determine if the mechanisms behind between-person IOR were activated because of the observers' understanding of their partner's response or because of the attention-capturing motion and/or effect of the response. The results indicate that the knowledge of the other person's behavior is the key factor, because between-person IOR was detected when there was no motion toward the target (Experiment 1) or any stimulus event occurring at the target location (Experiment 2A), but it was not observed when a nonbiological motion was present (Experiment 2B).

Although it is clear that between-person IOR results from an understanding of the other person's response, the neural systems that are responsible for the acquisition of this knowledge and the subsequent activation of the inhibitory mechanisms of IOR are less certain. From the available evidence, we suggest that the mirror neuron system is responsible for activating the inhibitory mechanisms of between-person IOR. The mirror neuron system in primates consists of a network of neurons that become active during both the performance and observation of action (e.g., di Pellegrino et al., 1992). We hypothesize that the activation of the mirror neuron system during the observation of the response mimicked the activity associated with the actual response, and subsequently activated the same inhibitory mechanisms that cause within-person IOR. This hypothesis is based on evidence that the observation of a response activates a representation of that response within cortical motor systems. For example, Gangitano, Mottaghy, and Pascual-Leone (2001) reported that the amplitude of the muscle potentials evoked via transcranial magnetic stimulation increased during the observation of action. Importantly, the potentials recorded from the muscles that were involved in the observed action were the potentials that demonstrated the biggest increase in amplitude. Thus, we suggest that these evoked neural patterns took the place of the neural codes of the actual response and subsequently activated the mechanisms of IOR. Although no electrophysiological data were collected in the present experiment, the findings that between-person IOR was observed during restricted viewing conditions known to activate mirror neurons - in which the observer only perceived the effect of the response (Experiment 1; Kohler et al., 2002) or saw only an initial segment of the response (Experiment 2A; Umiltà et al., 2001; Fogassi et al., 2005) - supports this hypothesis.

In sum, the present experiments demonstrate that the understanding of another person's behavior is a key factor contributing to IOR between individuals. The finding that the behavior of one person influences another's actions should be expected because humans have evolved as social animals. Although this influence can occur at the higher levels of cognition, such as learning and communication (Rizzolatti \& Craighero, 2004), the present study indicates that the actions of others can also have more immediate affects on the distribution of selective attention and motor programming (Sebanz, Knoblich, \& Prinz, 2003; see Sebanz, Bekkering, \& Knoblich, 2006, for a review).

\section{AUTHOR NOTE}

This research was funded by the Natural Sciences and Engineering Research Council of Canada, the Alberta Ingenuity Fund, and the Canada Research Chair program. The authors thank Melinda Wu, Matt Mercury, and Laura Higgins for their help with data collection and analysis. Correspondence concerning this article may be sent to T. N. Welsh, Faculty of Kinesiology, University of Calgary, 2500 University Drive NW, Calgary, AB, T2N 1N4 Canada (e-mail: twelsh@kin.ucalgary.ca). 


\section{REFERENCES}

Abrams, R. A., \& Christ, S. E. (2003). Motion onset captures attention. Psychological Science, 14, 427-432.

BAndura, A. (1977). Social learning theory. Englewood Cliffs, NJ: Prentice Hall.

Blandin, Y., Lhuisset, L., \& Proteau, L. (1999). Cognitive processes underlying observational learning of motor skills. Quarterly Journal of Experimental Psychology, 52A, 957-979.

di Pellegrino, G., Fadiga, L., Gallese, V., \& Rizzolatti, G. (1992). Understanding motor events: A neurophysiological study. Experimental Brain Research, 91, 176-180.

Fogassi, L., Ferrari, P. F., Gesierich, B., Rozzi, S., Chersi, F., \& Rizzolatti, G. (2005). Parietal lobe: From action organization to intention understanding. Science, 308, 662-667.

Gangitano, M., Mottaghy, F. M., \& Pascual-Leone, A. (2001). Phase-specific modulation of cortical motor output during movement observation. NeuroReport, 12, 1489-1492.

KLEIN, R. M. (1988). Inhibitory tagging system facilitates visual search. Nature, 334, 430-431.

KLEIN, R. M., \& MacInNEs, J. (1999). Inhibition of return is a foraging facilitator in visual search. Psychological Science, 10, 346-352.

Kohler, E., Keysers, C., Umiltà, M. A., Fogassi, L., Gallese, V., \& Rizzolatti, G. (2002). Hearing sounds, understanding actions: Action representation in mirror neurons. Science, 297, 846-848.

MAYloR, E. A., \& Hockey, R. (1985). Inhibitory component of externally controlled covert orienting in visual space. Journal of Experimental Psychology: Human Perception \& Performance, 11, 777-787.

Posner, M. I., \& COHEN, Y. (1984). Components of visual orienting. In H. Bouma \& D. G. Bouwhuis (Eds.), Attention and performance $X$ (pp. 531-556). Hillsdale, NJ: Erlbaum.

Rafal, R. D., Calabresi, P. A., Brennan, C. W., \& Sciolto, T. K. (1989). Saccade preparation inhibits reorienting to recently attended locations. Journal of Experimental Psychology: Human Perception \& Performance, 15, 673-685.

Rizzolatti, G., \& Craighero, L. (2004). The mirror-neuron system. Annual Review of Neuroscience, 27, 169-192.
Sebanz, N., Bekkering, H., \& Knoblich, G. (2006). Joint action: Bodies and minds moving together. Trends in Cognitive Sciences, $\mathbf{1 0}$, 70-76.

Sebanz, N., Knoblich, G., \& Prinz, W. (2003). Representing others' actions: Just like one's own? Cognition, 88, B11-B21.

Umiltà, M. A., Kohler, E., Gallese, V., Fogassi, L., Fadiga, L., KeySers, C., \& Rizzolatti, G. (2001). I know what you are doing: A neurophysiological study. Neuron, 31, 155-165.

Welsh, T. N., Elliott, D., Anson, J. G., Dhillon, V. P., Weeks, D. J., Lyons, J., \& ChuA, R. (2005). Does Joe influence Fred's action? Inhibition of return across different nervous systems. Neuroscience Letters, 385, 99-104.

Wilson, M., \& KNOBLICH, G. (2005). The case for motor involvement in perceiving conspecifics. Psychological Bulletin, 131, 460-475.

\section{NOTES}

1. Although there was only a single frame in which the stimulus was repositioned from the home position to the location $1 / 4$ of the distance to one of the targets (due to limitations in the refresh rate of the computer/ projection system and the temporal constraints resulting from the procedure of Experiment 2A), a perceptual effect of stimulus motion from the home position to the new location was present.

2. To compare the magnitudes of IOR in Experiment 2B and the partial-vision condition of Experiment 2A, RT data were submitted to a three-factor mixed ANOVA with Experiment (2A, 2B) as the betweensubjects factor and preceding movement (participant's own, partner/ virtual) $\times$ target (same, different) as the repeated measures factor. Although the three-way interaction between experiment, person, and target only approached conventional levels of significance $[F(1,29)=3.90$, $p<.058$ ], it is clear from the initial analyses (see main text) that there was an IOR effect in each condition except in the virtual-observation trials of Experiment 2B.

(Manuscript received July 25, 2006; revision accepted for publication December 1, 2006.) 